\title{
Methylphenidate improves executive functions in patients with traumatic brain injuries: a feasibility trial via the idiographic approach
}

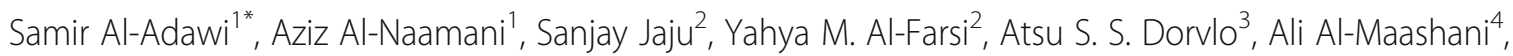
Sara S. H. Al-Adawi ${ }^{5}$, Ahmed A. Moustafa ${ }^{6}$, Nasser Al-Sibani ${ }^{1}$, Musthafa M. Essa ${ }^{7^{*}}$, David T. Burke ${ }^{8}$ and M. Walid Qoronfleh ${ }^{9^{*}}$

\begin{abstract}
Background: Road traffic accidents are known to be the main cause of traumatic brain injury (TBI). TBI is also a leading cause of death and disability. This study, by means of the idiographic approach (single-case experimental designs using multiple-baseline designs), has examined whether methylphenidate (MPH - trade name Ritalin) had a differential effect on cognitive measures among patients with TBI with the sequel of acute and chronic postconcussion syndromes. The effect on gender was also explored.

Methods: In comparison with healthy controls, patients with TBI (acute and chronic) and accompanying mild cognitive impairment $(\mathrm{MCl})$ were screened for their integrity of executive functioning. Twenty-four patients exhibiting executive dysfunction (ED) were then instituted with the pharmacological intervention methylphenidate $(\mathrm{MPH})$. The methylphenidate was administered using an uncontrolled, open label design.

Results: The administration of methylphenidate impacted ED in the TBI group but had no effect on mood. Attenuation of ED was more apparent in the chronic phases of TBI. The effect on gender was not statistically significant with regard to the observed changes.

(Continued on next page)
\end{abstract}

\footnotetext{
*Correspondence: samir-adawi@fulbrightmail.org; adawi@squ.edu.om; drmdessa@gmail.com; wqoronfleh@qf.org.qa

'Department of Behavioural Medicine, College of Medicine and Health Sciences, Sultan Qaboos University, Muscat, Oman

${ }^{7}$ Department of Food Science and Nutrition, College of Agricultural and

Marine Sciences, Sultan Qaboos University, Muscat, Oman

${ }^{9}$ Research \& Policy Department, World Innovation Summit for Health (WISH),

Qatar Foundation, P.O. Box 5825, Doha, Qatar

Full list of author information is available at the end of the article
}

(C) The Author(s). 2020 Open Access This article is licensed under a Creative Commons Attribution 4.0 International License, which permits use, sharing, adaptation, distribution and reproduction in any medium or format, as long as you give appropriate credit to the original author(s) and the source, provide a link to the Creative Commons licence, and indicate if changes were made. The images or other third party material in this article are included in the article's Creative Commons licence, unless indicated otherwise in a credit line to the material. If material is not included in the article's Creative Commons licence and your intended use is not permitted by statutory regulation or exceeds the permitted use, you will need to obtain permission directly from the copyright holder. To view a copy of this licence, visit http://creativecommons.org/licenses/by/4.0/ The Creative Commons Public Domain Dedication waiver (http://creativecommons.org/publicdomain/zero/1.0/) applies to the data made available in this article, unless otherwise stated in a credit line to the data. 


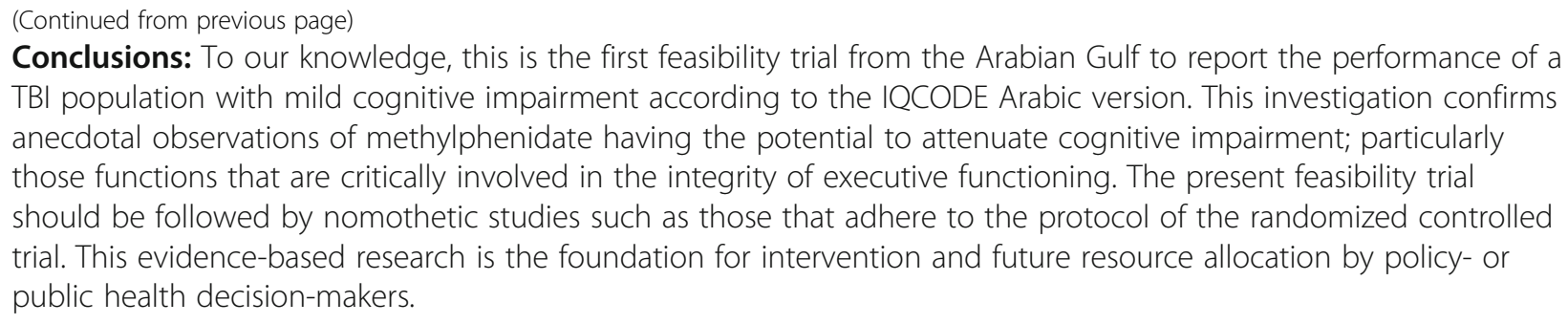

Keywords: Psychopharmacology, Executive functioning, Traumatic brain injury, TBI, Cognition, Depression, Anxiety, IQCODE, Methylphenidate, Ritalin

\section{Background}

At least 1 million people from all across the world sustain traumatic brain injury (TBI) each year [1]. Accompanying this statistic is an increasing recognition that TBI is a leading cause of death and disability [2-4] as well. Importantly, TBI typically seems to impact individuals under the age of 45 , a prime age for maximum human productivity [5]. Considering this fact, the situation is likely to be even more critical to the World Health Organization (WHO) classified 'Eastern Mediterranean' country of Oman, where $88.6 \%$ of the country's population falls within this age group [6].

In many Eastern Mediterranean countries, including Oman, road traffic accidents are known to be the main cause of TBI. It is estimated that road traffic accidents account for about 42 to $95 \%$ of all reported TBI cases. They are also a leading reason for death [7]. Each year, approximately 300 to 400 per 100,000 people in Oman suffer from TBI [7], translating roughly to a rate of 17 to 23 people per day. In a survey conducted by the Omani Ministry of Health [8], about 116 of the 17,791 individuals surveyed were involved in a "serious accident" in the preceding year. Approximately $11 \%$ of the 116 subjects were admitted to a hospital "for a long period", and at least $1.2 \%$ currently live with varying degrees of physical handicaps, including disability. Consequently, there has been growing interest in the field of disabilities and rehabilitation amongst brain-injured populations. In addition to various physical complications, a significant number of these patients struggle with cognitive impairments, particularly impairment of executive function [9], indicated to have poor prognostic indicators compared to those with amnesiac features [10]. However, there is a dearth of studies reporting this problem conducted in the Eastern Mediterranean despite the high rate of acquired brain injuries in the region [11].

Research from other populations have revealed that executive functioning can be manipulated by agents having an affinity for dopaminergic and noradrenergic systems [12-14]. In this regard, one of the most commonly used agents are methylphenidate (MPH-Ritalin): a neuro-stimulant postulated to increase synaptic dopamine and noradrenaline levels by blocking their reuptake, accordingly, heightening information processing [15]. Emerging views suggest a neurobiological and neurochemical basis for executive functioning involving the cortico-striatal-thalamo-cortical circuits $[16,17]$, as well as dopaminergic and noradrenergic systems [18, 19]. In support of this explanation, preclinical animal studies have shown that disrupting catecholaminergic projections to the frontal cortex results in deficits in working memory and executive functioning [20]. Damage to the frontal cortex may be expressed as impairments in working memory, self-directed, executive, cognitive functions including the reduction in the speed of information processing and concentration. The effects of frontal impairments due to TBI are pervasive as rehabilitation and quality of life (QoL) are likely to be impacted by cognitive deficits rather than overt physical disabilities.

Studies from developed countries show that the 'victim' of TBI tends first to receive critical care and later undergo neurorehabilitation in dedicated units where neuro-stimulants are instituted depending on the clinical and cognitive symptoms [4]. While neuro-stimulants are widely used to tease out their impact functional recovery [12-14], with few exceptions, there is a scarcity of studies shedding light on when is the most optimal time to commence initiation of neuro-stimulants. In the literature, the time elapsed since the injury is often reported to have been shown to range from a day to several years after initial TBI injury [21, 22]. There is no description of whether the participants were treated with methylphenidate during an acute or chronic post-TBI phase. Kaelin, Cifu \& Matthies [23] have operationalized acutely brain-injured adult those whose time since injury is approximately 2 months. Studies are therefore needed to shed light on whether acute ( $\leq 2$ months) or chronic phase ( $\geq 2$ months) is more responsive to neurostimulants.

In a TBI animal model, female sex hormones have been indicated to be critically involved in the modulation of 
dopaminergic and noradrenergic systems [24]. This would imply that there are likely to be a gender-specific response to compounds that have an affinity to dopaminergic and noradrenergic activities such as methylphenidate. In the clinical literature, investigations have suggested that there are gender-specific responses to methylphenidate [25, 26], but these studies are limited to non-TBI clinical populations. There is a lack of studies that have examined whether there are gender-specific responses to methylphenidate in the TBI population in the Eastern Mediterranean region and Oman is no exception. With the aforementioned literature review, this study has embarked to address the following aims: (i) to quantify whether treatment with methylphenidate improves executive functioning and mood in Omani patients with TBI and mild cognitive impairment and executive dysfunction, (ii) to measure the effect of methylphenidate on executive functioning and mood in acute or chronic phases of TBI, and (iii) to explore if the administration of methylphenidate and gender has a direct bearing on whether the patient is in the acute vs chronic phase. Previous studies have teased out the role of methylphenidate and cognitive enhancement. Most of the research on the TBI population are marred by a highly heterogeneous sample in the midst of heterogeneity of clinical and neuroimaging data [12, 13,
19, 21, 23]. This investigation is, therefore, constitute a feasibility trial with well defined executive dysfunction profiles that employed the idiographic approach, which is, single-subject experimental research designs using multiple-baseline designs (AABAA) that is equipped to accommodate the diversity and complexity of the TBI population [27].

\section{Methods}

\section{Setting}

Tertiary care is largely compartmentalized and centralized in Oman. The study sample consisted of Omani patients up to the age of 35 years who had sustained TBI and were referred to state-run tertiary care facilities at Sultan Qaboos University Hospital and Khoula Hospital for evaluation and treatment. Patients with TBI were prospectively enrolled between October 2015 and December 2016. The present study, therefore, constitutes a feasibility trial among TBI patients who were clinically evaluated as being amenable to routine pharmacological intervention.

\section{Participants}

For ethical approval see the such annotated section below for further consent and trial details. Also, Fig. 1

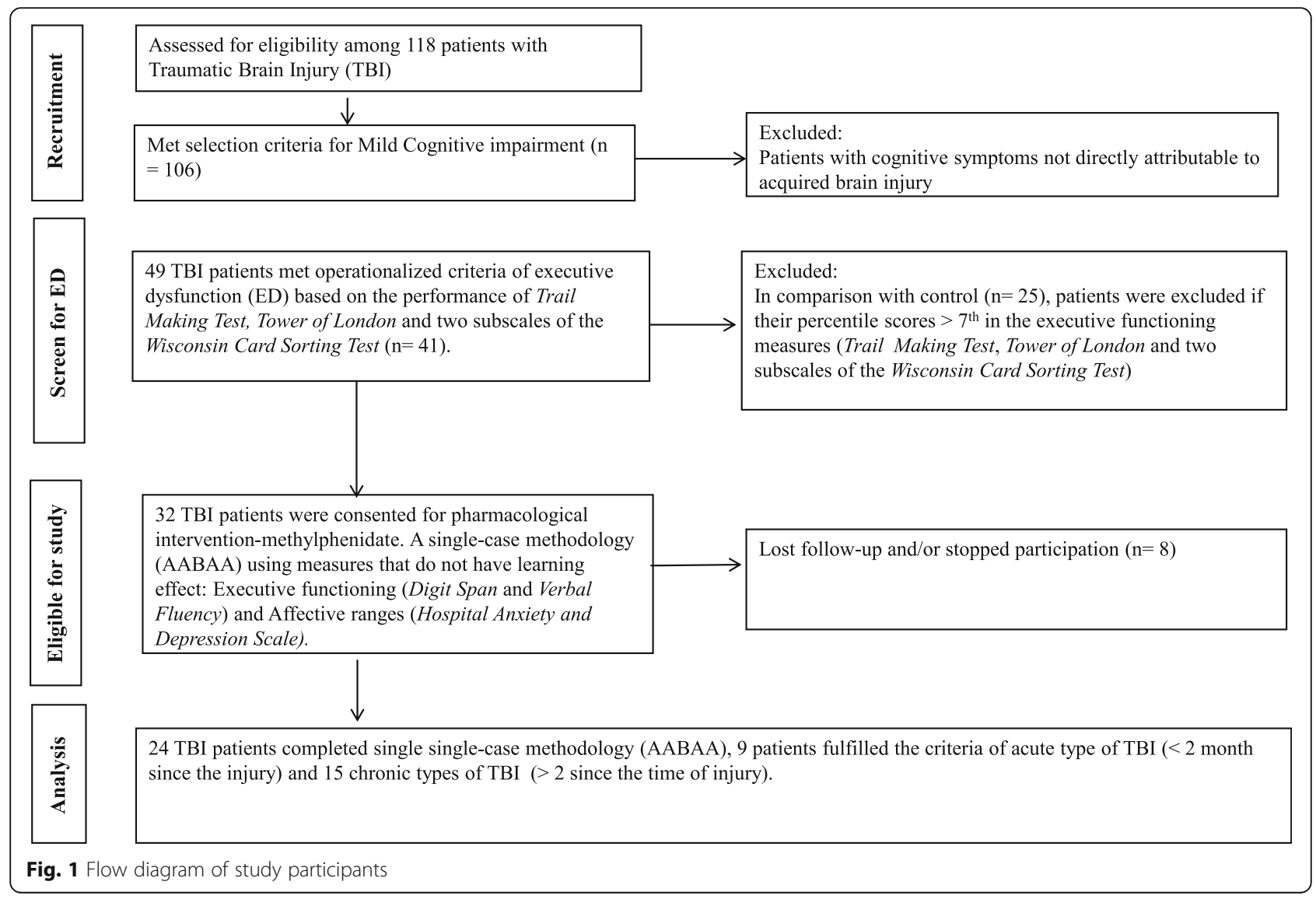


shows the study flowchart. Participants were identified clinically as being marked with cognitive impairment and presented pervasive impairment in learning and memory both in therapy and in their daily lives. The study inclusion criteria included participants with a documented history of a single TBI incident. TBI is defined here, as an injury to brain tissues caused by an external mechanical force, evidenced by a loss of consciousness, post-traumatic cognitive and behavioral changes or an objective neurological finding that can reasonably be attributed to the TBI on a physical or cognitive and behavioral status examination [28]. The second inclusion criteria are availability time since injury and other clinical risk factors as detailed in Table 1. The third inclusion criteria are participants fulfilling the criteria of mild cognitive impairment that would be selected via objective measure. The fourth inclusion criteria are that the participants manifest executive dysfunction. This was quantified using established neuropsychological measures where their percentile scores are $\leq 7$ in the executive functioning batteries. Executive functioning is a cognitive process that involves planning, decision making, error correction and troubleshooting [29]. It also involves situations where responses are not well-rehearsed, situations that require novel sequences of actions, and that require the overcoming of a strong habitual response or resisting temptation. Another final study inclusion is complete baseline data on the "Capacity to Consent to Treatment Instrument" [30].

Exclusion criteria include those with cognitive symptoms that are not directly attributable to the acquired brain injury. Similarly, the exclusion criterion included pre-injury, psychiatric or neurological histories other than those resulting from TBI and those presently on anti-seizure medication.

\section{Assessment of cognitive and affective ranges Cognitive functioning: mild cognitive functioning}

The presence of mild cognitive impairment was solicited via a validated Arabic version of the Informant Questionnaire on Cognitive Decline in the Elderly (IQCODE) [31]. As per established protocol, the accompanying family, who had been living with the respondent, was asked to fill out the IQCODE [31]. The items in the
IQCODE require the family member to identify what the individual was like before the TBI incident and to compare that with what the person is like now. The IQCODE is equipped to screen for the variation in cognitive functioning, which in turn suggests the presence of cognitive decline. The IQCODE-16 utilized the following scoring system: 'major improvement' $=1$, 'minor improvement' $=2$, 'did not change much' $=3$, 'minor deterioration' $=4$ and 'major deterioration' $=5$ [32]. For the present study, only patients with TBI endorsed to have 'minor deterioration' were included. Existing literature shows that 'minor deterioration' in IQCODE denotes mild cognitive impairment. The IQCODE has been established with high accuracy to identify the presence of mild cognitive impairment similar to other wellestablished examinations [33, 34].

\section{Cognitive functioning: executive functioning}

In the neuropsychological literature, the Wisconsin Card-Sorting Test, Tower of London and Trail Making Test are all considered essential for assessing some of the broader domains of executive dysfunction [35]. The modified Wisconsin Card-Sorting Test was used to gauge "set-shifting" and cognitive flexibility via two sub-scales: "Number of Categories Completed" and "Preservative Errors". The protocol for administering and scoring this test has been detailed in prior studies [36]. The Tower of London Test was employed to detect deficits in planning and the temporal organization of behavior [29, 37]; administration and scoring of this test have also been detailed in other studies [30, 38]. Lastly, the Trail Making Test was used to tap into cognitive processing speed, an integral part of executive functioning [39]. The scoring for the Trail Making Test was derived from two versions of the test, which were described elsewhere [35].

Digit Span (Wechsler Adult Intelligence Scale Subtest) is a scale with two components: Digits Forward and Digits Backward [40]. In the present context, only Digits Backward was employed; here the participant was read a random series of numbers and asked to repeat them in the reverse order (e.g., 9-1-3, should be repeated as 31-9). There is evidence to support the notion that Digits Backward rather Digits Forward is relevant to the integrity of executive functioning [41-43].

Table 1 Comparative assessment of executive functioning between traumatic brain injured Omani patients having mild cognitive impairment and healthy controls $(n=49)$

\begin{tabular}{|c|c|c|c|c|}
\hline \multicolumn{2}{|l|}{ Instrument } & \multirow{2}{*}{$\begin{array}{l}\text { TBI }(n=24) \\
156.75 \pm 76.4\end{array}$} & \multirow{2}{*}{$\begin{array}{l}\text { Control }(n=25) \\
90.16 \pm 13.29\end{array}$} & \multirow{2}{*}{$\frac{\text { P-value }}{<0.0001}$} \\
\hline Executive Functioning & Total score of Trail Making Test & & & \\
\hline & Categories completed from Wisconsin Card Sorting Test & $1.50 \pm 0.72$ & $3.72 \pm 0.46$ & $<0.0001$ \\
\hline & Perseverative errors from Wisconsin Card Sorting Test & $17.42 \pm 6.14$ & $3.12 \pm 3.44$ & $<0.0001$ \\
\hline & Tower of London & $10.00 \pm 4.86$ & $19.64 \pm 5.35$ & $<0.0001$ \\
\hline
\end{tabular}


Verbal Fluency (The Controlled Oral Word Association Test) [44] examines the initiation and speed of verbal responses. Participants were asked to produce as many different words that begin with three specific letters as possible, with one minute allowed per letter. Subjects were explicitly told not to repeat the same word twice, and not to use words that share a common root with a previously mentioned word (for example, fish, fishing, fisherman). Following these instructions, an example and a demonstration were provided so that the participants understood the task requirements, after which he/she was given each letter in turn. The total score for Verbal Fluency is the total number of different acceptable words produced across the three 60 -s periods [36]. In this experiment, the letters consisted of taa, raa, and waaw from the Arabic alphabet, as described in prior research [45]. The efficiency of verbal fluency has been linked to the integrity of the dorsolateral prefrontal cortex $[46,47]$.

\section{Affective ranges: anxiety and depressive symptoms} In order to rule out whether methylphenidate had a specific impact on executive functioning, the Hospital Anxiety and Depression Scale (HADS) [48] was administered to ascertain whether changes in the other measures were paralleled by alteration in anxiety and depression. The scale is a questionnaire composed of 14 items of which seven relating to depression while the other seven relating to anxiety. The psychometric properties of HADS were previously reported in the Omani population $[49,50]$.

\section{Socio-demographic and clinical risk factors}

In addition to cognitive and affective ranges, various socio-demographic and clinical data were sought from the medical records or from the accompanying family member(s) or the patients themselves including gender, age, education ('still in educational setting', 'completed college', 'some college', 'secondary', 'primary'), injury severity using Glasgow Coma Scale [51] (GCS; 'mild = 13 to 15 ', 'moderate $=9$ to 12 ', 'severe $=$ less than 9 '), and causes of TBI ('road traffic accident', 'fall'). The presence of neuropathology if any were reported in terms of brain scans (computerized tomography-CT and magnetic resonance imaging-MRI). The time since injury was also sought, which as defined as acute $(<2$ months since the TBI) or chronic ( $\geq 2$ months since the TBI) [52-56].

\section{Quantification of mild cognitive functioning and executive dysfunction}

In Oman and Arabic speaking population in general, there are no established measures to establish the presence of executive dysfunction. Therefore, the protracted exercises were needed to establish the presence of executive dysfunction. For quantification of mild cognitive impairment, the Informant Questionnaire on Cognitive Decline in the Elderly (IQCODE), was used. As shown in Fig. 1, IQCODE identified 106 out of 118 to meet the selection criteria for mild cognitive impairment.

The recognized 106 patients they were further scrutinized for the presence of executive functioning via their performance on the Wisconsin Card-Sorting Test, Tower of London Test and Trail Making Test that are known to be the sine-qua non for assessing executive functioning. Healthy volunteers were therefore recruited in order to establish the extent to which the TBI subjects with mild cognitive impairment 'deviated' from the healthy control group. The control population was recruited from amongst the staff of Sultan Qaboos University-SQU ( $n=$ $25)$. The healthy controls were matched for age, gender, and education. Inclusion for the control group included those with no history of medical, psychiatric or neurological conditions that warranted medical attention. This was orally confirmed for all consenting participants.

In order to quantify whether the TBI group exhibited executive dysfunction, z-values were computed for both the TBI and healthy control cohorts. Domain scores for each subject were calculated based on the mean test results of all tests from the respective domain. As detailed in other studies [29], tests were defined as indicating cases of executive dysfunction if the z-value was less than -1.5. A domain was judged as pathological if more than half of the included tests of the respective domain showed z-values below -1.5 or percentile $<7$ th. Table 2 highlights significant differences between the TBI group and the control group on the four administered tests for assessment of Executive Functioning (Trail Making Test, Tower of London Test and two sub-scales of the Wisconsin Card Sorting Test). In the Trail Making Test, the control group had an average of $90 \mathrm{~s}(\mathrm{SD}=13)$, while the TBI group took substantially longer (average of $157 \mathrm{~s}$ $(\mathrm{SD}=76)$ to complete the task $(p<0.001)$. In the Wisconsin Card Sorting Test, "Number of Categories Completed" and "Preservative Errors" were determined. In the former, TBI patients completed only 1.5 categories on average, which is significantly less than the control group who completed an average of 3.7 categories $(\mathrm{p}<$ 0.001 ). The patient group also had significantly more "Preservative Errors" compared to the control (17 vs 3; $\mathrm{p}<0.001)$. In the Tower of London Test, the control group scored nearly twice as high as the TBI patients (19.6 vs 10; $\mathrm{p}<0.001$ ) (Table 1). Therefore, as shown in Fig. 1, the participants with TBI $(n=49)$ met operationalized criteria of executive dysfunction.

\section{Protocol for a feasibility trial}

Participants with TBI $(n=32)$ with $\mathrm{z}$-values below -1.5 were deemed to suit the study criteria for feasibility trial with methylphenidate $(\mathrm{MPH})$ using AABAA single-case 
Table 2 Clinical and demographic characteristics of traumatic brain injured Omani participants with mild cognitive impairment and executive dysfunction

\begin{tabular}{|c|c|c|c|}
\hline Parameter & & No. of Patients & $\%$ of Patients \\
\hline \multirow[t]{2}{*}{ Gender } & Male & 13 & 54.2 \\
\hline & Female & 11 & 45.8 \\
\hline \multirow[t]{2}{*}{ Age } & $18-25$ & 17 & 70.8 \\
\hline & $26-35$ & 7 & 29.2 \\
\hline \multirow[t]{5}{*}{ Education } & Still in Educational setting & 5 & 20.8 \\
\hline & Completed College & 3 & 12.5 \\
\hline & Some College & 2 & 8.3 \\
\hline & Secondary & 11 & 45.8 \\
\hline & Primary & 3 & 12.5 \\
\hline \multirow[t]{4}{*}{ Injury severity } & Unknown & 3 & 12.5 \\
\hline & GCS (mild; 13 to 15) & 5 & 20.8 \\
\hline & GCS (moderate; 9 to 12) & 15 & 62.5 \\
\hline & GCS (severe; less than 9) & 1 & 4.2 \\
\hline \multirow[t]{3}{*}{ Causes of Traumatic Brain Injury } & Unknown & 2 & 8.3 \\
\hline & Road Traffic Accident & 20 & 83.3 \\
\hline & Fall & 2 & 8.3 \\
\hline \multirow[t]{2}{*}{ Time since injury } & Acute (< 2 months) & 9 & 37.5 \\
\hline & Chronic ( $\geq 2$ months) & 15 & 62.5 \\
\hline \multirow[t]{3}{*}{ Neuropathology (CT or MRI) } & Diffused & 6 & 25 \\
\hline & Bilateral Frontal Hematoma & 12 & 50 \\
\hline & Focal & 6 & 25 \\
\hline
\end{tabular}

$C T=$ Computed Tomography Imaging; $M R I=$ magnetic resonance imaging; $G S C=$ Glasgow Coma Scale

methodology as depicted below graphically (Table 3). The methylphenidate was administered using an uncontrolled, open label design which is explained below.

The assessments were conducted at baseline after the maximum dose of methylphenidate was instituted and the withdrawal of methylphenidate. Both Digit Span and Verbal Fluency circumvent the issue of practice or learning effect owing to the availability of various versions of these two measures and hence were used for successive

Table 3 Protocol design for the administration of methylphenidate that followed AABAA single case methodology

\begin{tabular}{ll}
\hline $\mathrm{A}$ & Baseline 1 (BL1) \\
${ }^{* \mathrm{~A}}$ & Baseline 2 (BL2) \\
${ }^{* * *} \mathrm{~B}$ & Maximum dose of methylphenidate (MAXMETH) \\
${ }^{* * *} \mathrm{~A}$ & Post-withdrawal 1 (POST1) \\
${ }^{* * *} \mathrm{~A}$ & Post-withdrawal 2 (POST2) \\
\hline
\end{tabular}

* BL2 evaluations conducted over 15 days of BL1 and then the institution of drug treatment (the starting dose was $5 \mathrm{mg} /$ day, increasing to a maximum dosage of $10 \mathrm{mg} /$ day)

** MAXMETH evaluations conducted at 30 days after BL2

*** Follow-up evaluations (POST1) were conducted at 15 days after the MAXMETH evaluation while POST2 was conducted after 15 days after POST1 assessments of the TBI patients. The baseline (BL) performance on cognitive measures constituted the average of two consecutive scores of the Digit Span and Verbal Fluency and similarly, the average of post-methylphenidate withdrawal (POST) performances was considered. The cognitive performance scores at a maximum dosage of methylphenidate were considered only once. Hospital Anxiety and Depression (HADS) was utilized to solicit the variations in anxiety and depression symptom in parallel with cognitive measures.

For the purpose of analysis of their responses, the patients were divided into two groups based on the time elapsed since the injury. Those whose time since injury was less than two months were operationalized as 'acute' TBI and the rest were operationalized as 'chronic TBI' [52]. The basic single-case methodology (AABAA) adopted was a repeated measure, with multiple baselines as shown above schematically. The second baseline assessments (A) was one week after the first baseline (A) and then (B) instituting methylphenidate (the starting dose was $5 \mathrm{mg} /$ day, increasing to a maximum dosage of $10 \mathrm{mg} /$ day). The assessment (B) took place when participants were in methylphenidate, that is, 30 days after the second baseline. Follow-up evaluations (POST1) were 
conducted at 15 days after the MAXMETH evaluation while POST2 was conducted after 15 days after POST1.

\section{Statistical analysis}

Statistical analysis was performed using SPSS Version 19. Summary tables were produced. $t$-tests and repeated ANOVA tests were used and $p$-values were reported in the tables.

\section{Ethical approval, trial withdrawal and discontinuation of trial medication}

This study was approved by the Institutional Review Board, 'Ethical Committee for Human and Clinical Research' and the 'Medical Research Committee' (Project No. MED 99-4) of of the College of Medicine \& Health Sciences, Sultan Qaboos University (SQU). Participants were requested to provide written informed consent which was also confirmed verbally again prior to data collection, and the study procedures were carried out in accordance with the Code of Ethics of the World Medical Association (Declaration of Helsinki of 1964-2008) for human experiments including confidentiality, privacy, documentation and data management. As for the trial withdrawal and discontinuation of trial medication, participants were explicitly informed that they are free to withdraw from the trial at any time without reason or impact on usual care. As shown in Fig. 1, only data from completed cycles were included in the analysis.

\section{Results}

Table 2 details clinical and demographic information of the TBI patients identified as having executive dysfunction (Fig. 1 provides the flowchart). Of the 32 patients, 24 completed the study (11 were female and 13 were male), however, 8 were lost at follow-up and/or stopped participation. Out of the 8,4 could not tolerate the medication. The majority had received education up to secondary school and above $(n=21)$. In terms of severity of the injury, 15 patients had moderate scores and 5 had mild scores on the Glasgow Coma Scale [57]. Neuroimaging data indicated that $25 \%(n=6)$ of the TBI group exhibited characteristics of diffused and focal brain injuries respectively, while $50 \% \quad(n=12)$ had frontal hematoma. Road traffic accidents were the major cause of TBI in this group (20 out of 24). Almost $63 \%$ of the cases were chronic cases. Nearly $50 \%$ had bilateral frontal hematoma as evidenced by computed tomography imaging or magnetic resonance imaging.

Further assessments of all TBI patients using stable cognitive measures (Verbal Fluency, Digit Span) and affective measures (anxiety and depression) across different time periods in comparison to baseline values are shown in Table 4. There was a significant rise in Digit Span results. A baseline reading of 4.00 (SD 0.81) increased to 5.71 (SD 0.81) following the administration of methylphenidate. The scores remained high at 5.88 (SD 1.87), post-methylphenidate withdrawal $(p<0.001$ in both situations). Verbal Fluency similarly exhibited a significant increase from the baseline score (9.33, SD 2.98) to scores obtained during methylphenidate treatment (12.38, SD 3.41; $\mathrm{p}<0.001)$ and post-withdrawal scores (12.21, SD 4.31; $p=0.008$ ).

The average HADS-Depression score of 7.02 (SD $2.63)$ at baseline decreased to 6.50 (SD 2.69) with methylphenidate administration $(p=0.033)$ but showed no significant change post-methylphenidate withdrawal with a score of 6.54 (SD 2.89) $(p=0.150)$. There was no significant change in the baseline result of anxiety (6.77, SD $3.45)$ from the results obtained after methylphenidate administration (6.88) and post-withdrawal (6.67).

Table 5 and Table 6 describe raw scores to examine whether acute $(<2$ months) or chronic phases of TBI $(\geq 2$ months) had any effect on executive functioning and mood after administration and later withdrawal of methylphenidate. Nine patients were in the acute phase of TBI during the study, these were seen less than two months after injury (four males and five females), and 15 were in the chronic phase of TBI, they were seen two or more months after the injury (nine males and six females). Based on their scores, both groups showed improvement in executive functioning following methylphenidate intervention. When executive functioning was assessed postwithdrawal, it was found that the acute group reverted to their original baseline scores, while the chronic group maintained the improved scores. Detailed analysis revealed that the TBI phase (i.e. acute vs chronic) had a substantial effect on executive functioning (Digit Span and Verbal Fluency), especially after correcting for baseline values (Table 7). Digit Span and Verbal Fluency scores were significantly higher than post-withdrawal scores for the chronic group, implying that methylphenidate enhanced executive functioning. The changes in HADS-Depression and HADS-Anxiety across the two TBI phases were not significant (Table 7).

Gender did not contribute to any significant difference in the scores of executive functioning and mood during methylphenidate treatment and after its withdrawal (Table 8).

\section{Discussion}

This feasibility trial has specifically employed the idiographic approach due to the nature of the TBI population whereby accruing a large sample size with the stable and homogeneous clinical data for neuropsychological evaluation and the pharmacological challenge is often untenable [58]. Such a cohort is, therefore, more apt to be studied using idiographic than a nomothetic approach. For example, as for the present cohort, $20 \%$ of 
Table 4 Measures of executive functioning (Verbal Fluency, Digit Span) and affective measures (HADS-Hospital and Depression Scale) across assessment occasions (baseline, during methylphenidate and post-withdrawal of methylphenidate) among a sample of Omanis with traumatic brain injury

\begin{tabular}{|c|c|c|c|c|c|c|c|}
\hline Category & Measure & Assessment & Min & Mean & Max & Std. Dev & $\mathrm{p}$ \\
\hline \multirow[t]{6}{*}{ Executive Functioning } & \multirow[t]{3}{*}{ Digit Span } & Average baseline & 3 & 4.00 & 6 & 0.81 & \\
\hline & & with methylphenidate & 4 & 5.71 & 7 & 0.81 & $p<0.001$ \\
\hline & & Average Post withdrawal & 3 & 5.88 & 8 & 1.87 & $p<0.001$ \\
\hline & \multirow[t]{3}{*}{ Verbal Fluency } & Average baseline & 3 & 9.33 & 16 & 2.96 & \\
\hline & & with methylphenidate & 7 & 12.38 & 18 & 3.41 & $p<0.001$ \\
\hline & & Average Post withdrawal & 5 & 12.21 & 19 & 4.31 & $P=0.008$ \\
\hline \multirow[t]{6}{*}{ Affective measures } & \multirow[t]{3}{*}{ HADS-Depression } & Average baseline & 2 & 7.02 & 13 & 2.63 & \\
\hline & & with methylphenidate & 2 & 6.50 & 13 & 2.69 & $p=0.033$ \\
\hline & & Average Post withdrawal & 2 & 6.54 & 13 & 2.89 & $p=0.150$ \\
\hline & \multirow[t]{3}{*}{ HADS-Anxiety } & Average Baseline & 2 & 6.77 & 15 & 3.45 & \\
\hline & & with methylphenidate & 2 & 6.88 & 15 & 3.31 & $p=0.732$ \\
\hline & & Average Post withdrawal & 2 & 6.67 & 15 & 3.31 & $p=0.719$ \\
\hline
\end{tabular}

*All comparisons indicated were with the baseline assessments

the patients were mild TBI and $62.5 \%$ were classified as moderate. In addition, only one patient experienced a severe TBI status. It is worth mentioning, that each injury level has a distinctly different prognosis and presentation by CT/MRI. Moreover, $37 \%$ of the patients were in the acute phase while $63 \%$ were in the chronic phase of injury. This feasibility trial explored three interrelated themes using idiographic-AABAA single experimental design.

The first aim was to investigate whether a sample of TBI patients would perform differently on measures of executive functioning when compared to a healthy population in Oman. Attributes that are most often viewed as defining a human being (e.g., reasoning, temporal organization of behavior, self-regulation, mental flexibility, aspects of attention and awareness) are some of the primary constituents of executive functioning. Furthermore, there is extensive empirical literature suggesting that executive dysfunction is one of the most debilitating and intransigent aspects of cognitive impairment typically acquired during traumatic brain injury $[59,60]$. To our knowledge, this is the first feasibility

Table 5 Descriptive statistics of executive functioning (Digit Span, Verbal Fluency) among a sample of Omanis with traumatic brain injury and accompanying mild cognitive impairment between time since injury and across different assessment periods based on gender

\begin{tabular}{|c|c|c|c|c|c|}
\hline \multicolumn{2}{|c|}{ Executive functioning } & \multirow{2}{*}{$\begin{array}{l}\text { Time since injury } \\
<2 \text { months }\end{array}$} & \multirow{2}{*}{$\begin{array}{l}\begin{array}{l}\text { Baseline }^{a} \\
\text { Mean, SD }\end{array} \\
3.67 \pm 1.00\end{array}$} & \multirow{2}{*}{$\begin{array}{l}\text { Methylphenidate }{ }^{b} \\
\text { Mean, SD } \\
5.22 \pm 0.83\end{array}$} & \multirow{2}{*}{$\begin{array}{l}\begin{array}{l}\text { Post withdrawal } \\
\text { Mean, SD }\end{array} \\
3.67 \pm 0.71\end{array}$} \\
\hline Digit Span & Total & & & & \\
\hline & & $\geq 2$ months & $4.20 \pm 0.86$ & $6.00 \pm 0.65$ & $7.20 \pm 0.68$ \\
\hline & Females & $<2$ months & $3.60 \pm 1.34$ & $5.40 \pm 0.89$ & $3.80 \pm 0.84$ \\
\hline & & $\geq 2$ months & $4.00 \pm 1.09$ & $6.00 \pm 0.89$ & $7.17 \pm 0.75$ \\
\hline & Males & $<2$ months & $3.75 \pm 0.05$ & $5.00 \pm 0.82$ & $3.50 \pm 0.58$ \\
\hline & & $\geq 2$ months & $4.33 \pm 0.70$ & $6.00 \pm 0.50$ & $7.22 \pm 0.68$ \\
\hline \multirow[t]{6}{*}{ Verbal Fluency } & Total & $<2$ months & $10.00 \pm 2.60$ & $12.44 \pm 2.83$ & $8.00 \pm 1.66$ \\
\hline & & $\geq 2$ months & $9.07 \pm 3.30$ & $12.33 \pm 3.81$ & $14.73 \pm 3.28$ \\
\hline & Females & $<2$ months & $8.80 \pm 2.05$ & $11.60 \pm 2.97$ & $7.80 \pm 1.09$ \\
\hline & & $\geq 2$ months & $8.33 \pm 3.61$ & $11.00 \pm 3.41$ & $13.50 \pm 4.18$ \\
\hline & Males & $<2$ months & $11.50 \pm 2.65$ & $13.50 \pm 2.65$ & $8.25 \pm 2.36$ \\
\hline & & $\geq 2$ months & $9.56 \pm 3.20$ & $13.22 \pm 3.99$ & $15.56 \pm 2.45$ \\
\hline
\end{tabular}

\footnotetext{
averages score across two baseline assessments

${ }^{b}$ Average scores across two post-intervention assessments

c The starting dose was $5 \mathrm{mg} /$ day, increasing to a maximum dosage of $10 \mathrm{mg} / \mathrm{day}$
} 
Table 6 Descriptive statistics of affective functioning (HADS-Hospital Anxiety and Depression Scale) among a sample of Omanis with traumatic brain injury suffering from mild cognitive impairment between time since injury and across different assessment periods based on gender

\begin{tabular}{|c|c|c|c|c|c|}
\hline \multicolumn{2}{|c|}{ Affective functioning } & \multirow{2}{*}{$\begin{array}{l}\text { Time since injury } \\
<2 \text { months }\end{array}$} & \multirow{2}{*}{$\begin{array}{l}\text { Baseline } \\
\text { Mean, SD } \\
7.90 \pm 3.73\end{array}$} & \multirow{2}{*}{$\begin{array}{l}\text { Methylphenidate } \\
\text { Mean, SD } \\
7.33 \pm 3.35\end{array}$} & \multirow{2}{*}{$\begin{array}{l}\text { Post withdrawal } \\
\text { Mean, SD } \\
6.78 \pm 4.05\end{array}$} \\
\hline HADS - & Total & & & & \\
\hline & & $\geq 2$ months & $6.50 \pm 1.61$ & $6.00 \pm 2.17$ & $6.4 \pm 2.06$ \\
\hline & Females & $<2$ months & $5.20 \pm 2.59$ & $5.20 \pm 2.49$ & $4.40 \pm 2.88$ \\
\hline & & $\geq 2$ months & $6.0 \pm 1.41$ & $5.67 \pm 2.06$ & $5.83 \pm 1.32$ \\
\hline & Males & $<2$ months & $11.25 \pm 1.26$ & $10.00 \pm 2.16$ & $9.75 \pm 3.40$ \\
\hline & & $\geq 2$ months & $6.67 \pm 1.73$ & $6.22 \pm 2.33$ & $6.78 \pm 2.44$ \\
\hline \multirow{6}{*}{$\begin{array}{l}\text { HADS - } \\
\text { Anxiety }\end{array}$} & Total & $<2$ months & $5.44 \pm 3.64$ & $6.00 \pm 3.35$ & $5.89 \pm 3.48$ \\
\hline & & $\geq 2$ months & $7.40 \pm 3.31$ & $7.40 \pm 3.29$ & $7.13 \pm 3.22$ \\
\hline & Females & $<2$ months & $5.40 \pm 3.78$ & $6.40 \pm 3.13$ & $6.20 \pm 3.42$ \\
\hline & & $\geq 2$ months & $9.00 \pm 3.95$ & $8.50 \pm 3.62$ & $8.50 \pm 3.62$ \\
\hline & Males & $<2$ months & $5.50 \pm 4.04$ & $5.50 \pm 4.04$ & $5.50 \pm 4.04$ \\
\hline & & $\geq 2$ months & $6.33 \pm 2.50$ & $6.67 \pm 3.04$ & $6.22 \pm 2.77$ \\
\hline
\end{tabular}

trial from the Arabian Gulf to report the performance of a TBI population with mild cognitive impairment performing poorly on measures of executive functioning compared to a healthy control group, according to an Arabic version of Informant Questionnaire on Cognitive Decline in the Elderly (IQCODE) [32]. In prior studies, there has been a debate on whether mild cognitive impairment is a prodromal stage of neurogenerative disorders or 'normal' variation of cognitive functioning [61]. In the general population, the constituent of mild cognitive impairment has been postulated to include illdefined memory impairment, intact global cognitive and intellectual capacity and no overt symptoms of dementia [62]. This feasibility trial suggests that in a TBI population, there is impairment of executive functioning among those who fulfilled the criteria of mild cognitive impairment, a view previously noted by others [63, 64].

Huang et al. [58], in their meta-analysis, have identified 683 published studies that have reported the use of methylphenidate for the TBI population from electronic databases. These studies employed the spectrum of cognitive measures. The authors concluded that methylphenidate has the potential to mostly enhancing attentional capacity but not memory or processing speed. There have been indications that some pharmacological approaches may be useful in addressing aspects of executive dysfunction [65, 66], but no studies have been forthcoming from the Eastern Mediterranean. This feasibility trial suggests that treatment with the catecholaminergic agonist, methylphenidate, impacted executive dysfunction. Averaging across all participants, methylphenidate treatment did not produce any significant changes in mood, suggesting that pharmacological intervention impacted cognitive functioning directly rather than via the patients' affected state. Discussions in the current literature on whether cognitive functioning is influenced by mood or, conversely, whether the mood is influenced by the level of cognitive functioning, are ongoing $[67,68]$. This interpretation is consistent with systematic and meta-analytic reviews suggesting the lack of effectiveness of methylphenidate in mitigating symptoms of depression [69]. It is worthwhile to note that mood state was measured using the 'symptom checklist', HADS. Future studies should employ more robust measures such as a semi-structured diagnostic interview, the 'gold standard'.

Table 7 Effect of Methylphenidate on Executive (Digit Span and Verbal Fluency) and Anxiety and Depression tapped by Hospital Anxiety and Depression Scale (HADS)

\begin{tabular}{lll}
\hline Classification & During the treatment period & Post withdrawal period \\
\hline & $\boldsymbol{P}^{\text {-value }}$ using the baseline as covariate $^{-}$ & $\leq 0.001$ \\
Digit Span & 0.051 & $\leq 0.001$ \\
Verbal Fluency & 0.334 & 0.169 \\
HADS - Depression & 0.933 & 0.415 \\
HADS - Anxiety & 0.625 &
\end{tabular}

$P$-values for comparisons over the time since injuryand Depression Scale (HADS) across gender 
Table 8 Effect of Methylphenidate on Digit Span and Verbal Fluency (Executive) and Anxiety and Depression from Hospital Anxiety and Depression Scale (HADS) across gender.

\begin{tabular}{lll}
\hline Classification & During the treatment period & Post withdrawal period \\
\hline & P-value* $^{*}$ using the baseline as covariate & 0.895 \\
Digit Span & 0.677 & 0.237 \\
Verbal Fluency & 0.400 & 0.614 \\
HADS - Depression & 0.492 & 0.824 \\
HADS - Anxiety & 0.891 & \\
\hline
\end{tabular}

*P-values for comparing males against females

The TBI population in Oman has had no access to dedicated restorative therapies [70]. An enduring theme in prior studies is the tendency for a majority of braininjured patients to recover spontaneously. Another issue is the establishment of a window of recovery for cognitive impairment. Therefore, deciphering when to intervene is imperative. This feasibility trial indicates that time since the injury has an effect on cognitive measures (Digit Span and Verbal Fluency). These measures appear to have been robustly affected in the "chronic" cohort. In contrast, the performance on affective measures has little bearing on whether the participants belong to the "acute" or "chronic" group. Furthermore, the observed improvement with methylphenidate administration was maintained after withdrawal in only the "chronic" group, but not the "acute" group. This essentially seems to suggest that the administration of methylphenidate is more effective for the "chronic" group. This raises the question as to whether the improvement in cognitive function scores can be attributed to the effect of methylphenidate, or whether it is simply part of spontaneous recovery. Despite such a caveat, the consistent baseline scores and sudden improvement found only after pharmacological intervention suggest that the improvements were indeed attributed to chronicity and methylphenidate. Future studies might explore when it is optimal to use methylphenidate on a TBI population.

In prior work, there has been a dearth of studies examining the trajectory of time since injury, intervention, and outcome in TBI. What constitutes acute or chronic is sometimes inferred in terms of 'primary' and 'secondary injury' [53]. Primary injury has been operationalized as a time period immediately following injury [54]. Secondary damage is characterized by complications starting within minutes, hours, days or even months after primary injury and includes different events such as changes in gene expressions, inflammation, ischaemia, central immunomodulation disturbance, impaired energy metabolism and neuronal death [55, 56]. These variations of such a cascade of pathological processes have a direct bearing on the functional outcome [71]. There is some evidence to suggest that secondary injury may not be triggered directly by trauma, but rather a combination of primary injury and the resultant array of pathological processes. A clear-cut demarcation between primary and secondary injury has yet to be established. Undoubtedly, tudies to define what constitutes acute and chronic phases of TBI are needed. As this feasibility trial suggests, such demarcation might lead to prognostic indicators of when neuro-stimulants are used.

Previously, females have shown have poorer prognostic indicators and recovery compared to males [72]. This feasibility trial ostensibly discounts the issue of gender in executive functioning. The findings suggest no significant difference between male and female patients on all measures. Furthermore, it appears that methylphenidate has the potential to attenuate symptoms of executive dysfunction in both genders. Some studies shedding light on how and why methylphenidate works on executive functioning have emerged. Methylphenidate has been suggested to trigger modulation of the catecholaminergic system or specifically, its capability to attenuate reuptake of dopamine and norepinephrine neurotransmission in the brain [19]. Interestingly catecholaminergic neuron has been shown to innervate cortical and subcortical regions thought to be critically involved in executive functioning in primates [73]. In human beings, compounds with affinity to the catecholaminergic system such as methylphenidate have been shown to heighten executive functioning and its neural substrate in the human brain [64]. Thus, reflecting on prior scholarly work, the present finding largely supports the previous contention that executive functioning can be manipulated with compounds that affect dopaminergic and noradrenergic systems [74-76].

An important finding in the present feasibility trial was that the improvement did not reverse following drug withdrawal. Although this feasibility trial was not equipped to investigate the issue of pharmacologically induced neuroplasticity, there are some anecdotal and clinical observations indicating that neuro-stimulants, such as methylphenidate, have had the capacity to "kickstart" spontaneous recovery [36]. One opinion suggests brain injury triggers the cascade of excitotoxity [77, 78]. Interestingly, there is evidence to propose that such 
excitotoxity can be 'scavenged' by the catecholaminergic system $[79,80]$, for example, when methylphenidate is exogenously induced $[77,81]$.

\section{Limitations}

Despite that non-parametric statistics were utilized to observe changes across baseline, intervention and postwithdrawal periods, some limitations of the feasibility trial ought to be highlighted. First and foremost, this feasibility trial is limited by being an open-label study (i.e., not double blinded and with no control group), a cohort with homogeneity of injuries and a relatively small sample size. Despite fulfilling the requirement of the idiographic study, when a feasibility trial is scrutinized under the prism of the nomothetic microscope, are likely to be seen with several limitations. Therefore, this feasibility trial should lay the groundwork for randomized clinical trials. Secondly, this feasibility trial could have employed another catecholaminergic agonist compound other than methylphenidate to validate findings. Thirdly, the generalizability of this feasibility trial might be lacking because it did not include motor and functional metrics to complement present neurocognitive metrics. Related to assessment, this feasibility trial has embarked to quantify the presence of mild cognitive impairment using IQCODE. In addition to controversies on what constitutes mild cognitive impairment [82], IQCODE lacks the vigor of the other bedside measures such as Montreal Cognitive Assessment (MoCA) and Mini-Mental State Examination (MMSE) for soliciting the presence of cognitive decline but there are dissenting views [31, 83]. IQCODE has been validated in the Arabic speaking population and appears to have good psychometric properties [31, 33, 34]. Future studies should employed other conventional neuropsychological measures to tap into the presence of mild cognitive impairment. Other than IQCODE, the present feasibility trial has utilized strong non-verbal components or those that have been employed in the Arabic-speaking population previously. With a few exceptions, the majority of the measures do not have cutoffs for the TBI population in Oman. For these reasons, protracted exercises were taken to establish 'caseness' for executive dysfunction. For these reasons, 'caseness' for executive dysfunction was derived from the z-values $(-1.5)$ or percentile $=<$ 7 th) as previously reported elsewhere [29]. Fourthly, it might be theoretically interesting to include another cohort of TBI rather than those with executive functioning. This might increase the scientific merit of the current feasibility trial. Fifthly, in Oman, the demography is characterized by a pyramidal-like population structure with the majority as a youth. Indeed, the previous survey in Oman has indicated that the majority of the victim of the road traffic accident and TBI are youngster [84]. In a population of younger TBI patients as the present cohort, it likely that noted 'improvements' could stem from many factors including placebo effect, spontaneous recovery, and/ or developmental changes as the brain is well established to continue growth until $\sim$ age 25 . The present study, open-label, was not equipped to circumvent these confounders. Additional studies using a vigorous research methodology are needed to shed further light on the trajectory between time since injury, neuropsychological recovery, and the impact of a number of commonly used pharmacological agents on braininjured populations.

\section{Conclusions}

Despite traumatic brain injury being a global challenge, issues pertinent to the disability it triggers and the rehabilitation that is needed in emerging economies, such as Oman, have received scant attention in past literature. The present study utilized a feasibility trial to explore whether treatment with methylphenidate, in patients with TBI, would improve executive functioning. The investigation was uncontrolled, open label design. The study results suggested that methylphenidate tended to positively impact executive functioning. The study outcome also suggested that noted improvement was most heavily dictated by time elapsed since the injury. Unlike prior research, there was no gender difference in executive functioning or response to treatment. An unpredicted finding in the present study was that improvements did not reverse following drug withdrawal among those patients operationalized in the "chronic" group. Being a feasibility trial, it is important for future studies to scrutinize these present findings through a study design with a more robust methodology. Finally, we believe this is an important feasibility study in this population. In the future, we want to extend this work into randomized controlled trial (RCT) to address limitations, strengthen findings that supports the conclusion and confirmation of methylphenidate treatment. This evidence-based research is valuable to both public health officials and policy decision-makers in order to design and implement policies that improve health and social outcomes.

\section{Abbreviations \\ CT: Computerized Tomography; ED: Executive Dysfunction; GCS: Glasgow Coma Scale; HADS: Hospital Anxiety and Depression Scale; \\ IQCODE: Informant Questionnaire on Cognitive Decline in the Elderly; MCI: Mild Cognitive Impairment; MPH: Methylphenidate; MRI: Magnetic Resonance Imaging; QoL: Quality of Life; RCT: Randomized Controlled Trial; SD: Standard Deviation; TBI: Traumatic Brain Injury; WHO: World Health Organization}

\section{Acknowledgements}

The authors thank the study staff and the staff at Sultan Qaboos University Hospital for their support. They thank the survivors of traumatic brain injury and the volunteers that offered their support by participating in this study.

The authors also want to thank their respective institutions for their 
continued support. The Qatar National Library (QNL), Doha, Qatar, funded the publication of this article.

\section{Ethics and consent approval}

Written informed consent was obtained from all participants prior to data collection. The study and consent form details were approved by both the 'Ethical Committee for Human and Clinical Research' and the 'Medical Research Committee' (Project No. MED 99-4) of the College of Medicine, Sultan Qaboos University. This study adhered to the World Medical Association's Declaration of Helsinki (1964-2008) for Ethical Human Research including confidentiality, privacy and data management.

\section{Authors' contributions}

SA and AD performed statistical analysis. AN, SJ, YMF, SSHA, AAM, NA and DTB conducted the behavioral assessment, collected information, and generated short write-ups. AM led patients recruitment. SA, MME and MWQ conceptual work, framework, draft write-up and editing. All authors read and approved the final manuscript.

\section{Funding}

This research received no specific grant from any funding agency in the public, commercial, or not-for-profit sectors.

\section{Availability of data and materials}

This is a research article and all data generated or analyzed during this study are included in this published article.

\section{Consent for publication}

Not applicable.

\section{Competing interests}

None. The authors declare that there are no conflicts of / or competing interests.

\section{Author details}

${ }^{1}$ Department of Behavioural Medicine, College of Medicine and Health Sciences, Sultan Qaboos University, Muscat, Oman. ${ }^{2}$ Department of Family Medicine and Public Health, College of Medicine and Health Sciences, Sultan Qaboos University, Muscat, Oman. ${ }^{3}$ Department of Mathematics and Statistics, College of Science, Sultan Qaboos University, Muscat, Oman. ${ }^{4}$ Department of Neurosurgery, Khoula Hospital, Ministry of Health, Muscat, Oman. ${ }^{5}$ Oman Medical Specialty Board, Muscat, Oman. ${ }^{6}$ School of Social Sciences and Psychology, Marcs Institute of Brain and Behaviour, Western Sydney University, Penrith, NSW, Australia. ${ }^{7}$ Department of Food Science and Nutrition, College of Agricultural and Marine Sciences, Sultan Qaboos University, Muscat, Oman. ${ }^{8}$ Department of Rehabilitation Medicine, Emory University School of Medicine, Atlanta, GA, USA. ${ }^{9}$ Research \& Policy Department, World Innovation Summit for Health (WISH), Qatar Foundation, P.O. Box 5825, Doha, Qatar.

\section{Received: 16 May 2019 Accepted: 27 February 2020}

Published online: 19 March 2020

\section{References}

1. Lecky F, Bouamra O, Woodford M. Changing epidemiology of Polytrauma. In damage control Management in the Polytrauma Patient 2017 (pp. 27-32). Springer International Publishing.

2. GBD. Mortality and Causes of Death Collaborators. Global, regional, and national age-sex specific all-cause and cause-specific mortality for 240 causes of death, 1990-2013: A systematic analysis for the global burden of disease study 2013. Lancet 2015. 2013;385(9963):117-71.

3. Taylor CA. Traumatic brain injury-related emergency department visits, hospitalizations, and deaths-United States, 2007 and 2013. MMWR Surveill Summ. 2017:66.

4. Sun KM, Song KJ, Shin SD, Tanaka H, Shaun GE, Chiang WC, Kajino K, Jamaluddin SF, Kimura A, Ro YS, Wi DH. Comparison of emergency medical services and trauma care systems among Pan-Asian countries: an international, multicenter. Prehosp Emerg Care. 2017;21(2):242-51.

5. Gore FM, Bloem PJ, Patton GC, Ferguson J, Joseph V, Coffey C, Sawyer SM, Mathers CD. Global burden of disease in young people aged 10-24 years: a systematic analysis. Lancet. 2011;377(9783):2093-102.
6. Current population of Oman - Countrymeters. Oman population 2017. http://countrymeters.info/en/Oman.

7. Al-Reesi H, Ganguly SS, Al-Adawi S, Laflamme L, Hasselberg M, Al-Maniri A. Economic growth, motorization, and road traffic injuries in the Sultanate of Oman, 1985-2009. Traffic Inj Prev. 2013;14(3):322-8.

8. Al-Naamani A, Al-Adawi S. 'Flying coffins' and neglected neuropsychiatric syndromes in Oman. Sultan Qaboos Univ Med J. 2007;7(2):75-81.

9. Al-Adawi S, Al-Naamani A, Al-Farsi Y, Essa MM, Burke DT, El-Bouri M, Amstrong K, Edwards J, Al-Muscati S, MacFarland AS, Al MA. Elucidating the neuropsychological profile of apathetic syndrome and disinhibition syndrome in a brain-injured population in Oman. Int J Nutr Pharmacol Neurol Dis. 2016;6:35-45.

10. Al-Adawi S1, Braidy N, Essa M, Al-Azri F, Hussain S, Al-Sibani N, Al-Khabouri J, Al-Asmi A, Al-Mashani A. Cognitive profiles in patients with multi-infarct dementia: an Omani study. Dement Geriatr Cogn Dis Extra 2014 4(2): 271 282. doi: https://doi.org/10.1159/000363621

11. Al-Adawi S, Dorvlo AS, Burke DT, Huynh CC, Jacob L, Knight R, Shah MK, AlHussaini A. Apathy and depression in cross-cultural survivors of traumatic brain injury. J Neuropsychiatry Clin Neurosci. 2004 Fall;16(4):435-42.

12. Wheaton P, Mathias JL, Vink R. Impact of pharmacological treatments on cognitive and behavioural outcome in the postacute stages of adult traumatic brain injury: a meta-analysis. J Clin Psychopharmacol. 2011;31(6):745-57.

13. Frenette AJ, Kanji S, Rees L, Williamson DR, Perreault MM, Turgeon AF, Bernard F, Fergusson DA. Efficacy and safety of dopamine agonists in traumatic brain injury: a syste matic review of randomized controlled trials. J Neurotrauma. 2012;29(1):1-18.

14. McDowell S1, Whyte J, D'Esposito M. Differential effect of a dopaminergic agonist on prefrontal function in traumatic brain injury patients. Brain. 1998; 121(PT 6): 1155-1164.

15. Zimmer L. Contribution of Clinical Neuroimaging to the Understanding of the Pharmacology of Methylphenidate Trends. Pharmacol Sci. 2017;38(7): 608-20. https://doi.org/10.1016/j. Tips. 2017.04.001.

16. Hayes JP, Miller DR, Lafleche G, Salat DH, Verfaellie M. The nature of white matter abnormalities in blast-related mild traumatic brain injury. Neuroimage Clin. 2015;8:148-56.

17. Cristofori I, Zhong W, Chau A, Solomon J, Krueger F, Grafman J White and grey matter contributions to executive function recovery after traumatic brain injury. Neurology. 2015;84(14):1394-401.

18. Castellanos FX, Tannock R. Neuroscience of attention-deficit/hyperactivity disorder: the search for endophenotypes. Nat Rev Neurosci. 2002;3:617-28.

19. Arnsten AF, Li BM. Neurobiology of executive functions: catecholamine influences on prefrontal cortical functions. Biol Psychiatry. 2005 Jun 1;57(11): $1377-84$

20. Podet A, Lee MJ, Swann AC, Dafny N. Nucleus accumbens lesions modulate the effects of methylphenidate. Brain Res Bull. 2010;82(5-6):293-301.

21. Eshel I, Marion DW. Traumatic brain injury (TBI): current diagnostic and therapeutic challenges. InTraumatic brain injury 2020 (pp. 421-437). Springer, Cham

22. Chen A, Novakovic-Agopian T, Loya F. Interventions to improve cognitive functioning after traumatic brain injury (TBI). In: Tsao J, editor. Traumatic brain injury. Cham: Springer; 2020.

23. Kaelin DL, Cifu DX, Matthies B. Methylphenidate effect on attention deficit in the acutely brain-injured adult. Arch Phys Med Rehabil. 1996 Jan 1;77(1): 6-9.

24. Wagner AK, Kline AE, Ren D, Willard LA, Wenger MK, Zafonte RD, Dixon CE. Gender associations with chronic methylphenidate treatment and behavioral performance following experimental traumatic brain injury. Behav Brain Res. 2007;181(2):200-209. doi: https://doi.org/10.1016/j.bbr.2007. 04.006. Epub 2007 Apr 20. PMID: 17517440; PMCID: PMC1974874.

25. Davis C, Fattore L, Kaplan AS, Carter JC, Levitan RD, Kennedy JL. The suppression of appetite and food consumption by methylphenidate: the moderating effects of gender and weight status in healthy adults. Int J Neuropsychopharmacol. 2012 Mar 1;15(2):181-7.

26. Goldfield GS, Lorello C, Cameron J, Chaput JP. Gender differences in the effects of methylphenidate on energy intake in young adults: a preliminary study. Appl Physiol Nutr Metab. 2011:36(6):1009-13.

27. Kazdin AE. Single-case research designs: methods for clinical and applied settings. New York: Oxford University Press; 1982.

28. Menon DK, Schwab K, Wright DW, Maas Al. Demographics and Clinical Assessment Working Group of the International and Interagency Initiative toward Common Data Elements for Research on Traumatic Brain Injury and 
Psychological Health. Position statement: Definition of traumatic brain injury. Arch Phys med Rehabil. 2010;91(11):1637-40. https://doi.org/10.1016/ j. apmr. 2010.05.017.

29. Toledo JB, Bjerke M, Chen K, Rozycki M, Jack CR Jr, Weiner MW, Arnold SE, Reiman EM, Davatzikos C, Shaw LM, Trojanowski JQ. Alzheimer's Disease Neuroimaging Initiative. Memory, executive, and multidomain subtle cognitive impairment, Clin Biomarker Findings. Neurol. 2015;85(2):144-53. https://doi.org/10.1212/WNL.0000000000001738.

30. Hooper SM, Chiong W. Decision-making capacity and frontal lobe dysfunction. In, Bruce L. Miller and Jeffrey L. Cummings. The human frontal lobes: functions and disorders-third edition 2017; pp. 184-199. New York: Guilford Press.

31. Phung TKT, Chaaya M, Asmar K, Atweh S, Ghusn H, Khoury RM, Waldemar G. Performance of the 16-item informant questionnaire on cognitive decline for the elderly (IQCODE) in an Arabic-speaking older population. Dement Geriatr Cogn Disord. 2015:40:276-89.

32. Bou-Orm IR, Khamis AM, Chaaya M. Determinants of poor cognitive function using A-IQCODE among Lebanese older adults: a cross-sectional study. Aging Ment Health. 2018 Jun;22(6):844-8. https://doi.org/10.1080/ 13607863.2017.1301879.

33. Mackinnon A, Mulligan R. Combining cognitive testing and informant report to increase accuracy in screening for dementia. Am J Psychiatr. 1998:155:1529-153.

34. Harrison JK, Stott DJ, McShane R, Noel-Storr AH, Swann-Price RS, Quinn TJ. Informant Questionnaire on Cognitive Decline in the Elderly (IQCODE) for the early diagnosis of dementia across a variety of healthcare settings. Cochrane Database Syst Rev. 2016;11:CD011333.

35. Al-Adawi S, Al-Zakwani I, Obeid YA, Zaidan Z. Neurocognitive functioning in women presenting with undifferentiated somatoform disorders in Oman. Psychiatry Clin Neurosci. 2010;64(5):555-64.

36. Al-Adawi S1, Powell JH, Greenwood RJ. Motivational deficits after brain injury: a neuropsychological approach using new assessment techniques. Neuropsychology 1998; 12(1): 115-124.

37. Shallice T. Specific impairments of planning. Philos Trans R Soc Lond Ser B Biol Sci. 1982;298(1089):199-209.

38. Bishop DV1, Aamodt-Leeper G, Creswell C, McGurk R, Skuse DH. Individual differences in cognitive planning on the Tower of Hanoi task: neuropsychological maturity or measurement error? J Child Psychol Psychiatry 2001; 42(4): 551-556.

39. Arnett JA, Labovitz SS. Effect of physical layout in performance of the trail making test. Psychol Assess. 1995;7(2):220-1.

40. Wechsler D. The Wechsler intelligence scale for children-fourth edition (WISC-IV). San Antonio, TX: The Psychological Corporation; 2003.

41. Gerton BK, Brown T, Meyer-Lindenberg A, Kohn P, Holt JL, Olsen RK, Berman KF. Shared and distinct neurophysiological components of the digits forward and backward tasks as revealed by functional neuroimaging. Neuropsychologia. 2004;42(13):1781-7.

42. Rosenthal EN1, Riccio CA, Gsanger KM, Jarratt KP. Digit Span components as predictors of attention problems and executive functioning in children. Arch Clin Neuropsychol. 2006;21(2): 131-139.

43. Demery JA, Larson MJ, Dixit NK, Bauer RM, Perlstein WM. Operating characteristics of executive functioning test following traumatic brain injury. Clin Neuropsychol. 2010;24(8):1292-308.

44. Benton AL. Differential behavioural effects of frontal lobe disease. Neuropsychologia. 1968;6:53-60.

45. Al-Ghatani AM, Obonsawin M, Al Moutaery KR. Normative data for the two equivalent forms of the Arabic verbal fluency test. Pan Arab J Neurosurg. 2009;13(2):57-65.

46. Nishimura $Y$, Takizawa R, Koike S, Kinoshita A, Satomura $Y$, Kawasaki S, Yamasue H, Tochigi M, Kakiuchi C, Sasaki T, Iwayama Y, Yamada K, Yoshikawa T, Kasai K. Association of decreased prefrontal hemodynamic response during a verbal fluency task with EGR3 gene polymorphism in patients with schizophrenia and in healthy individuals. Neuroimage. 2014; 85(PT 1):527-34

47. Krueger CE, Laluz V, Rosen HJ, Neuhaus JM, Miller BL, Kramer JH. Double dissociation in the anatomy of socioemotional disinhibition and executive functioning in dementia. Neuropsychology. 2011;25(2):249-59.

48. Zigmond AS, Snaith RP. The hospital anxiety and depression scale. Acta Psychiatr Scand. 1983;67(6):361-70.

49. Al-Asmi A, Dorvlo AS, Burke DT, Al-Adawi S, Al-Zaabi A, Al-Zadjali HA, AlSharbati Z, Al-Adawi S. The detection of mood and anxiety in people with epilepsy using two-phase designs: experiences from a tertiary care Centre in Oman. Epilepsy Res. 2012;98(2-3):174-81.
50. Al-Adawi S, Dorvlo AS, Al-Naamani A, Glenn MB, Karamouz N, Chae H, Zaidan ZA, Burke DT. The ineffectiveness of the hospital anxiety and depression scale for diagnosis with an Omani traumatic brain injured population. Brain Inj. 2007;21(4):385-93.

51. Zafonte RD, Hammond FM, Mann NR, Wood DL, Black KL, Millis SR. Relationship between Glasgow coma scale and functional Outcome1. Am J Phys Med Rehab. 1996;75(5):364-9.

52. Conti AC, Raghupathi R, Trojanowski JQ, Mclntosh TK. Experimental brain injury induces regionally distinct apoptosis during the acute and delayed post-traumatic period. J Neurosci. 1998 Aug 1;18(15):5663-72.

53. Porth, C Essentials of Pathophysiology: Concepts of Altered Health States. Hagerstown, MD: Lippincott Williams \& Wilkins, 2007.

54. Zhou H. Moderate traumatic brain injury triggers rapid necrotic death of immature neurons in the hippocampus. J Neuropathology Exp Neurol. 2012;71:348-59.

55. Ziebell JM, Morganti-Kossmann MC. Involvement of pro- and antiinflammatory cytokines and chemokines in the pathophysiology of traumatic brain injury. Neurotherapeutics. 2010 Jan;7(1):22-30. https://doi. org/10.1016/j.nurt.2009.10.016.

56. DeKosky ST, Blennow K, Ikonomovic MD, Gandy S. Acute and chronic traumatic encephalopathies: pathogenesis and biomarkers. Nat Rev Neurol. 2013;9(4):192-200. https://doi.org/10.1038/nrneurol. 2013.36.

57. Teasdale GR, Jennett BR. Assessment and prognosis of coma after head injury. Acta Neurochir. 1976;34(1-4):45-55.

58. Huang $\mathrm{CH}$, Huang CC, Sun $\mathrm{CK}$, Lin GH. Hou WH1. Methylphenidate on cognitive improvement in patients with traumatic brain injury: a metaanalysis. Curr Neuropharmacol. 2016;14(3):272-81.

59. McDonald BC, Flashman LA, Saykin AJ. Executive dysfunction following traumatic brain injury: neural substrates and treatment strategies. NeuroRehabilitation. 2002;17(4):333-44.

60. Sami MB, Faruqui R. The effectiveness of dopamine agonists for treatment of neuropsychiatric symptoms post brain injury and stroke. Acta Neuropsychiatr. 2015:8:1-11.

61. Winblad B, Palmer K, Kivipelto M, Jelic V, Fratiglioni L, Wahlund LO, Nordberg A, Bäckman L, Albert M, Almkvist O, Arai H, Basun H, Blennow K, de Leon M, DeCarli C, Erkinjuntti T, Giacobini E, Graff C, Hardy J, Jack C, Jorm A, Ritchie K, van Duijn C, Visser P, Petersen RC. Mild cognitive impairment--beyond controversies, towards a consensus: report of the international working group on mild cognitive impairment. J Intern Med. 2004 Sep;256(3):240-6.

62. Morris JC, Storandt M, Miller JP, McKeel DW, Price JL, Rubin EH, Berg L. Mild cognitive impairment represents early-stage Alzheimer disease. Arch Neurol. 2001 Mar;58(3):397-405.

63. MCAllister TW, Sparling MB, Flashman LA, Guerin SJ, Mamourian AC, Saykin AJ. Differential working memory load effects after mild traumatic brain injury. Neuroimage. 2001 Nov;14(5):1004-12.

64. Mehta MA1, Owen AM, Sahakian BJ, Mavaddat N, Pickard JD, Robbins TW. Methylphenidate enhances working memory by modulating discrete frontal and parietal lobe regions in the human brain. J Neurosci 2000; 20(6): RC65.

65. Kim J, Whyte J, Patel S, Europa E, Wang J, Coslett HB, Detre JA. Methylphenidate modulates sustained attention and cortical activation in survivors of traumatic brain injury: a perfusion fMRI study. Psychopharmacology (Berl). 2012 ;222(1):47-57. doi: https://doi.org/10.1007/ s00213-011-2622-8. Epub 2011 Dec 28. PMID: 22203319; PMCID: PMC3369011.

66. Kochanek PM, Jackson TC, Ferguson NM, Carlson SW, Simon DW, Brockman EC, Ji J, Bayır H, Poloyac SM, Wagner AK, Kline AE, Empey PE, Clark RS, Jackson EK, Dixon CE. Emerging therapies in traumatic brain injury. Semin Neurol. 2015;35(1):83-100.

67. Fann JR, Uomoto JM, Katon WJ. Cognitive improvement with treatment of depression following mild traumatic brain injury. Psychosomatic. 2001 JanFeb;42(1):48-54.

68. Silver JM1, McAllister TW, Arciniegas DB. Depression and cognitive complaints following mild traumatic brain injury. Am J Psychiatry 2009; 166(6): 653-661. doi: https://doi.org/10.1176/appi. ajp. 2009.08111676.

69. Mclntyre RS1, Lee Y, Zhou AJ, Rosenblat JD, Peters EM, Lam RW, Kennedy $\mathrm{SH}$, Rong C, Jerrell JM. The Efficacy of Psychostimulants in Major Depressive Episodes: A systematic review and meta-analysis. J Clin Psychopharmacol 2017; 37(4): 412-418. doi: https://doi.org/10.1097/JCP.0000000000000723.

70. Al Naamani A. Neuropsychiatric Syndromes in the Survivors of Traumatic Brain Injury in Oman: An examination of disorder of self-neglect (Doctoral 
dissertation, Research Space@Auckland, The University of Auckland). https:// researchspace.auckland.ac.nz/handle/2292/23939.

71. Werner C, Engelhard K. Pathophysiology of traumatic brain injury. Br J Anaesth. 2007 Jul;99(1):4-9.

72. Iverson GL, Gardner AJ, Terry DP, Ponsford JL, Sills AK, Broshek DK, Solomon GS. Predictors of clinical recovery from concussion: a systematic review. Br J Sports Med. 2017 Jun;51(12):941-8. https://doi.org/10.1136/bjsports-2017097729.

73. Arnsten AF, Cai JX, Murphy BL, Goldman-Rakic PS. Dopamine D1 receptor mechanisms in the cognitive performance of young adult and aged monkeys. Psychopharmacology. 1994;116:143-51.

74. Pflibsen L, Stang KA, Sconce MD, Wilson VB, Hood RL, Meshul CK, Mitchell $\mathrm{SH}$. Executive function deficits and glutamatergic protein alterations in a progressive 1-methyl-4-phenyl-1,2,3,6-tetrahydropyridine mouse model of Parkinson's disease. J Neurosci Res. 2015. https://doi.org/10.1002/Jnr. 23638.

75. Yan HQ, Osier ND, Korpon J, Bales JW, Kline AE, Wagner AK, Dixon CE. Persistent cognitive deficits: implications of altered dopamine in traumatic brain injury. In: Kobeissy FH (Editor). Brain Neurotrauma: molecular, neuropsychological, and rehabilitation aspects. Boca Raton (FL): CRC Press; 2015. Chapter 33. http://www.ncbi.nIm.nih.gov/books/NBK299215/.

76. Coull JT, Sahakian BJ, Hodges JR. The alpha (2) antagonist idazoxan remediates certain attentional and executive dysfunction in patients with dementia of frontal type. Psychopharmacology. 1996 Feb;123(3):239-49.

77. Kline AE, Chen MJ, Tso-Olivas DY, Feeney DM. Methylphenidate treatment following ablation-induced hemiplegia in the rat: experience during drug action alters effects on recovery of function. Pharmacol Biochem Behav. 1994;48(3):773-9.

78. Feeney, DM. From laboratory to clinic: noradrenergic enhancement of physical therapy for stroke or trauma patients. In Freund, HJ, Sabel, BA Witte, OW (editors). Brain Plasticity: Advances in Neurology 1997; 73: 383394.

79. Darbar A, Stevens RT, Siddiqui AH, McCasland JS, Hodge CJ. Pharmacological modulation of cortical plasticity following kainic acid lesion in rat barrel cortex. J Neurosurg. 2008;109(1):108-16.

80. Sonde L, Lökk J. Effects of amphetamine and/or L-dopa and physiotherapy after stroke - a blinded randomized study. Acta Neurol Scand. 2007;115(1): 55-9.

81. Kline AE, Massucci JL, Marion DW, Dixon CE. Attenuation of working memory and spatial acquisition deficits after a delayed and chronic bromocriptine treatment regimen in rats subjected to traumatic brain injury by controlled cortical impact. J Neurotrauma. 2002 Apr 1;19(4):415-25.

82. Jak AJ, Bondi MW, Delano-Wood L, Wierenga C, Corey-Bloom J, Salmon DP, Delis DC. Quantification of five neuropsychological approaches to defining mild cognitive impairment. Am J Geriatr Psychiatry. 2009 ;17(5):368-375. doi: https://doi.org/10.1097/JGP.0b013e31819431d5. PMID: 19390294; PMCID: PMC2743175.

83. Dong Y, Sharma VK, Chan BP, Venketasubramanian N, Teoh HL, Seet RC, Tanicala S, Chan YH, Chen C. The Montreal cognitive assessment (MoCA) is superior to the mini-mental state examination (MMSE) for the detection of vascular cognitive impairment after acute stroke. J Neurol Sci. 2010 Dec 15; 299(1-2):15-8.

84. Al Reesi H, Al Maniri A, Adawi SA, Davey J, Armstrong K, Edwards J. Prevalence and characteristics of road traffic injuries among young drivers in Oman, 2009-2011. Traffic Inj Prev. 2016 Jul 3;17(5):480-7. https://doi.org/ 10.1080/15389588.2015.1107679.

\section{Publisher's Note}

Springer Nature remains neutral with regard to jurisdictional claims in published maps and institutional affiliations.

Ready to submit your research? Choose BMC and benefit from:

- fast, convenient online submission

- thorough peer review by experienced researchers in your field

- rapid publication on acceptance

- support for research data, including large and complex data types

- gold Open Access which fosters wider collaboration and increased citations

- maximum visibility for your research: over $100 \mathrm{M}$ website views per year

At BMC, research is always in progress.

Learn more biomedcentral.com/submissions 